\title{
Diurnal variations in the excretion of faeces and urine by sheep fed once daily or at hourly intervals
}

\author{
BY D. J. MINSON \\ Division of Tropical Pastures, CSIRO, Cooper Laboratory, \\ Lawes, Queensland \\ AND J. L. COWPER \\ Division of Tropical Pastures, CSIRO, Cunningham Laboratory, \\ Brisbane, Queensland
}

(Received 7 February 1966-Accepted 6 June 1966)

\begin{abstract}
I. A machine is described which automatically releases previously weighed rations to individually penned sheep at hourly intervals for $24 \mathrm{~h}$. 2 . Six sheep were kept in a room with constant light, temperature and continuous background noise and given $912 \mathrm{~g}$ lucerne daily at $10.00 \mathrm{~h}$ or at hourly intervals by means of the automatic feeder. Faeces and urine were collected every $2 \mathrm{~h}$. 3 . Hourly feedings reduced the variation between 2 -hourly collection periods by $47,87,90,85,70$ and $91 \%$ for total dry-matter content of the faeces, faeces drymatter concentration, total urine output, urine specific gravity, urine nitrogen concentration and total $\mathrm{N}$ content of the urine respectively.
\end{abstract}

The behaviour and metabolism of animals kept under normal environmental conditions are not constant, but are subject to diurnal variations. These variations often cause difficulty in interpreting observations recorded at one particular time of the day (Brody, 1945). This difficulty has usually been overcome by making observations at different times after feeding (Meyer, Gaskill, Stoewsand \& Weir, 1959). This is often inconvenient and requires a large number of measurements to be taken. A second method of overcoming this problem is to reduce and if possible eliminate completely the diurnal variations.

Diurnal variations in animals are associated with diurnal variations in the environment. Morris (I96I) eliminated the diurnal rhythm of egg laying in chickens by keeping them in a continuously lighted chamber; background noise was masked by a radio tuned to a $24 \mathrm{~h}$ continuous radio service.

When the external environment remains constant and feed is available at all times, sheep might be expected to exhibit a random pattern of feeding behaviour. By replacing a diurnal with a random behaviour pattern, biases due to sampling time will be eliminated and the variability in physiological processes reduced if the periodicity of the average random pattern is less than that of the original diurnal rhythm. In practice, it is difficult to achieve an absolutely constant environment. It may also take a long time to break previously existing patterns of behaviour unless the experimental animals are fed at frequent intervals (Brody, I945). Murray, Reid \& Sutherland (1962) used a moving belt to allow sheep to consume feed evenly over a $24 \mathrm{~h}$ period and Pritchard \& Heaney (1963) fed sheep at hourly intervals with an automatic feeding device in a study of the distribution of digesta in the alimentary 
tract of sheep. However, the feeders were not described and no results were presented to show that the method reduced diurnal variations.

This paper describes an automatic feeding device used in a controlled environment to reduce diurnal variations in sheep and presents findings demonstrating advantages of the system.

\section{EXPERIMENTAL}

\section{Automatic feeder}

The machine stands on top of two sheep metabolism cages and delivers feed at hourly intervals for $24 \mathrm{~h}$ (Pl. r). Weighed hourly rations are placed in twenty-four trays ( 27 in $\times 2$ in $\times 3.5$ in deep) divided in the centre to separate the two rations. The trays are attached to two 250 -link bicycle chains by spare links fitted every fifth link at right angles to the chain. Each tray is attached to the chains at the corners adjacent to the underside of the leading edge.

When the chains move forward, the front tray falls through $200^{\circ}$, throwing the contents into two chutes leading to the feed bins in front of the sheep. Every time the trays move forward, a bell rings to disturb the sheep and inform the attendant working outside the room that the machine is working.

The chains run on fifteen-toothed sprockets attached to steel shafts of diameter 0.75 in. The front shaft revolves at $4.5 \mathrm{rev} / \mathrm{min}$, and is driven by a $0.05 \mathrm{hp}$ electric motor. The 'master' unit motor and bell is switched on every hour by a time switch. After the front shaft has revolved through $120^{\circ}$ the circuit is broken by a ball microswitch operating on a cam attached to this shaft; a copy of the circuit may be obtained from the authors. To feed six sheep, two additional 'slave' feeder units without controls are connected to the 'master' feeder by an extension to the front shaft.

After $24 \mathrm{~h}$ the trays are returned to the refill position on top of the machine by means of a handle attached to the front shaft. The tension on the driving belt is released by lifting the spring-loaded motor mounting.

\section{Sheep and the controlled environment}

Six two-tooth merino wethers were each fitted with a harness and canvas faeces bag and kept in a metabolism crate fitted with a urine chute and automatic feeder. To eliminate diurnal variations in light intensity, the sheep were kept in a blacked-out room ( $20 \mathrm{ft} \times \mathrm{I}_{4} \mathrm{ft}$ ) continually lit by four $40 \mathrm{~W}$ fluorescent tubes. Temperature was maintained at $25^{\circ}$ with a $\mathrm{I} \cdot 5 \mathrm{hp}$ air-conditioning unit. No attempt was made to eliminate variations in the relative humidity. Diurnal variations occurred in the level of sound outside the room which could affect the behaviour of the sheep, so a radio tuned to a $24 \mathrm{~h}$ programme was used to reduce this effect.

\section{Feeding}

All sheep were given 9 I2 $\mathrm{g}$ air-dried lucerne hay daily, containing $89.7 \%$ dry matter, $4 . \mathrm{I} \% \mathrm{~N}$ and $9 \cdot 2 \%$ ash. The digestibility of the dry matter was $65.0 \%$.

In the first experiment the entire daily ration was offered at $10.00 \mathrm{~h}$ each morning for 12 days and the time taken to eat the hay was recorded on the last 2 days. In Expt 2 
the sheep were given $3^{8} \mathrm{~g}$ lucerne every hour for 12 days, the automatic feeder being used; feeding was on the hour.

\section{Measurements}

The faeces and urine were collected from each sheep and weighed every $2 \mathrm{~h}$ on days II and $\mathrm{I} 2$ in both experiments. The dry-matter content of the faeces was determined by drying at $100^{\circ}$. After weighing, the urine of the six sheep was mixed, the specific gravity was determined with a hydrometer and the concentration of $\mathrm{N}$ by the Kjeldahl method.

\section{RESULTS}

\section{Eating time}

In Expt I the entire ration was eaten within $4^{-6} \mathrm{~h}$. When fed at hourly intervals in Expt 2 the sheep began eating the hourly allowance immediately after it had dropped into the feed bin and had eaten it within $5 \mathrm{~min}$.

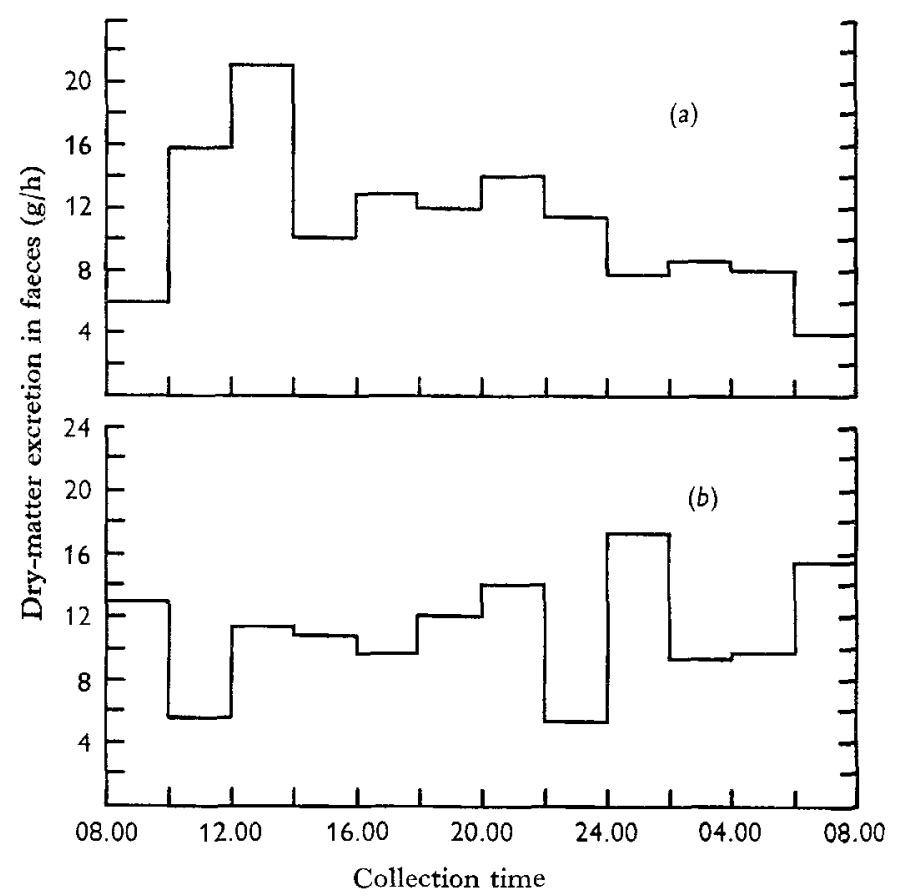

Fig. 1. Diurnal variation in the excretion of faeces dry matter in sheep given feed $(a)$ once, at $10.00 \mathrm{~h}$, or $(b)$ twenty-four times daily. (Mean values for six sheep for 2 days.)

\section{Faecal dry-matter excretion}

When the sheep were given food once each day there was a marked diurnal variation in the faecal output (Fig. I). The quantity of faeces dry matter produced in the $2 \mathrm{~h}$ after the sheep began to feed was three times greater than the mean for the previous $4 \mathrm{~h}$. Between noon and $\mathrm{I} 4.00 \mathrm{~h}$ faecal excretion was four times greater. The rate remained fairly constant during the next $10 \mathrm{~h}$ and then decreased steadily until the 
next feed. The mean excretion rate was $10.95 \mathrm{~g} / \mathrm{h}$ and the standard deviation of the hourly excretion rate $\pm 4.62 \mathrm{~g}$.

Feeding at hourly intervals eliminated the high excretion rate between $10.00 \mathrm{~h}$ and I $4.00 \mathrm{~h}$ and the low excretion rate between $06.00 \mathrm{~h}$ and $10.00 \mathrm{~h}$ (Fig. I). Hourly feeding reduced the variation in the quantity of faeces produced in the 2-hourly collection periods, the standard deviation being reduced to $\pm 3.50 \mathrm{~g} / \mathrm{h}$ and the variance by $47 \%$. The rate of excretion was not constant and an analysis of variance of the faecal excretion in the twenty-four $2 \mathrm{~h}$ collection periods showed that the differences between collection periods were significant $(P<0.05)$. The total quantity of faeces produced in the $48 \mathrm{~h}$ collection periods was $3 \%$ greater for the sheep fed at hourly intervals. The difference was not significant $(P>0.05)$.

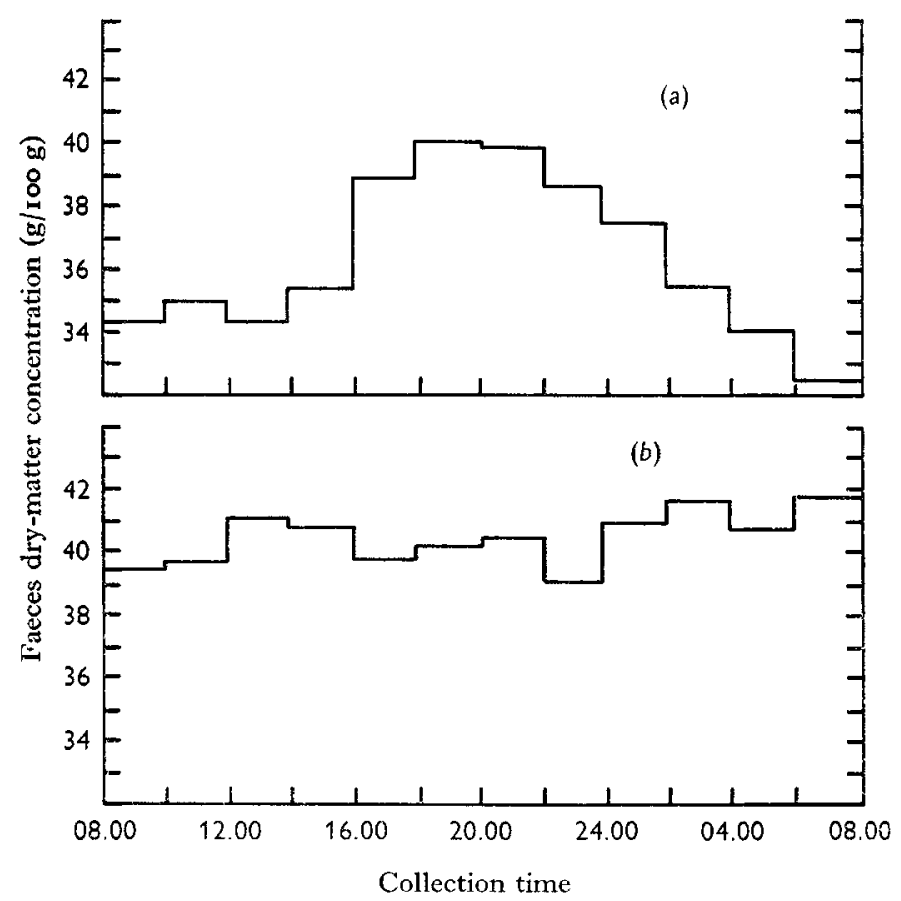

Fig. 2. Diurnal variation in concentration of faecal dry matter in sheep given feed (a) once, at $\mathrm{I} 0.00 \mathrm{~h}$, or $(b)$ twenty-four times daily. (Mean values for six sheep for 2 days.)

\section{Faecal dry-matter concentration}

In Expt I the dry-matter concentration increased from $32.6 \%$ at $06.00-08.00 \mathrm{~h}$ to $40.0 \%$ I 2 h later (Fig. 2). The dry-matter concentration in the 2-hourly collections had a standard deviation of $\pm 2 \cdot 74 \%$. When the sheep were fed at hourly intervals the dry-matter concentration varied between 39.5 and $4 \mathrm{I} \cdot 7 \%$ with a standard deviation of $\pm \mathrm{r} \cdot 00 \%$ and the variance between collection periods was reduced by $87 \%$. None of the differences between 2-hourly collection periods was significant $(P>0.05)$ when the sheep were fed every hour. 


\section{Urine flow}

A diurnal rhythm in urine flow occurred when the sheep were fed once each day, with significant $(P<0.05)$ differences in 2-hourly flow rates and a standard deviation of $\pm 23^{\cdot} \mathrm{I}$ g. The variance was reduced by $90 \%$ (SD $\pm 7 \cdot 4 \mathrm{~g}$ ) when the sheep were fed at hourly intervals. With hourly feeding, $15 \%$ less urine was excreted in $48 \mathrm{~h}$, but the difference was not significant $(P>0.05)$.

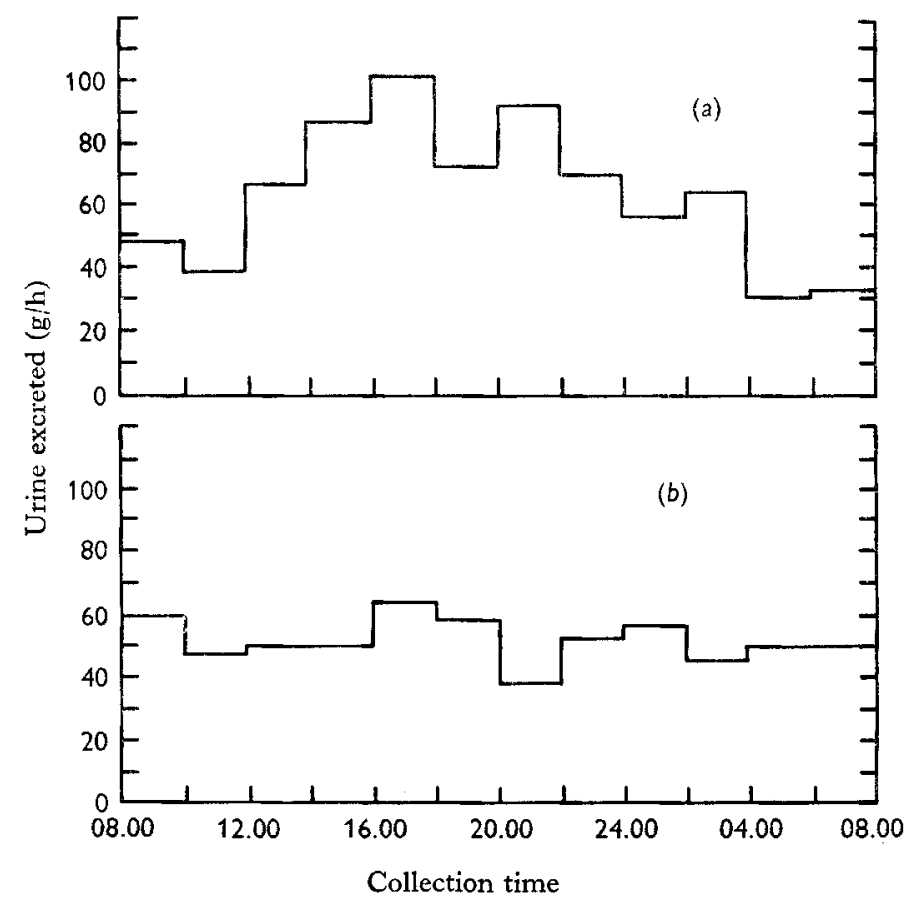

Fig. 3. Diurnal variation in urine excretion in sheep given feed $(a)$ once, at $10.00 \mathrm{~h}$, or (b) twenty-four times daily. (Mean values for six sheep for 2 days.)

\section{Urine specific gravity}

When the sheep were fed once daily the specific gravity was highest $4-6 \mathrm{~h}$ after feeding, and lowest between midnight and $02.00 \mathrm{~h}$ (Fig. 4). The standard deviation when the urine was collected at $2 \mathrm{~h}$ intervals was \pm 0.075 . Feeding at hourly intervals eliminated the diurnal variation, reduced the 2 -hourly variance by $85 \%$ and the standard deviation to \pm 0.029 .

\section{Urine $N$ concentration}

With once-daily feeding the maximum $\mathrm{N}$ concentration in the urine occurred in the $2 \mathrm{~h}$ before feeding. The level remained high for $8 \mathrm{~h}$ after feeding and dropped to a minimum $6 \mathrm{~h}$ later. The standard deviation with the 2-hourly collections was $\pm 0.28 \mathrm{~g} / \mathrm{I} 00 \mathrm{ml}$. Hourly feeding eliminated the diurnal variation, reduced the 2-hourly variance by $70 \%$ and the standard deviation to $\pm 0.18 \mathrm{~g} / 100 \mathrm{ml}$ (Fig. 5). 


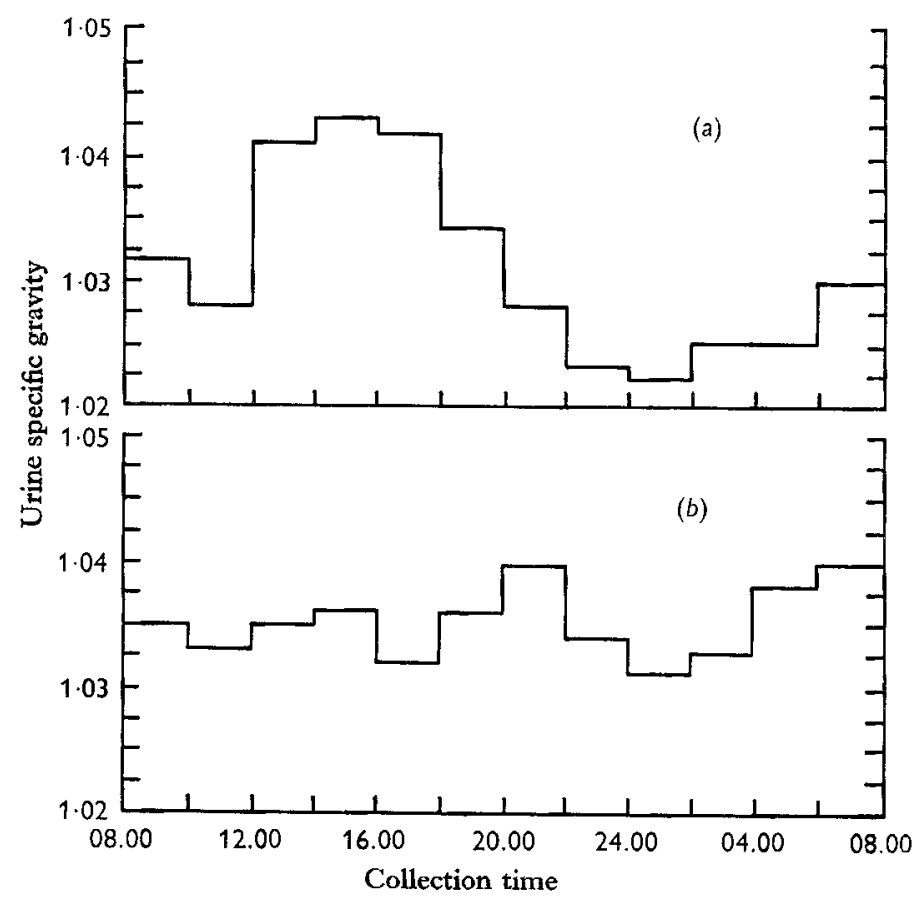

Fig. 4. Diurnal variation in urine specific gravity in sheep given feed $(a)$ once, at $10.00 \mathrm{~h}$, or (b) twenty-four times daily. (Mean values for six sheep for 2 days.)

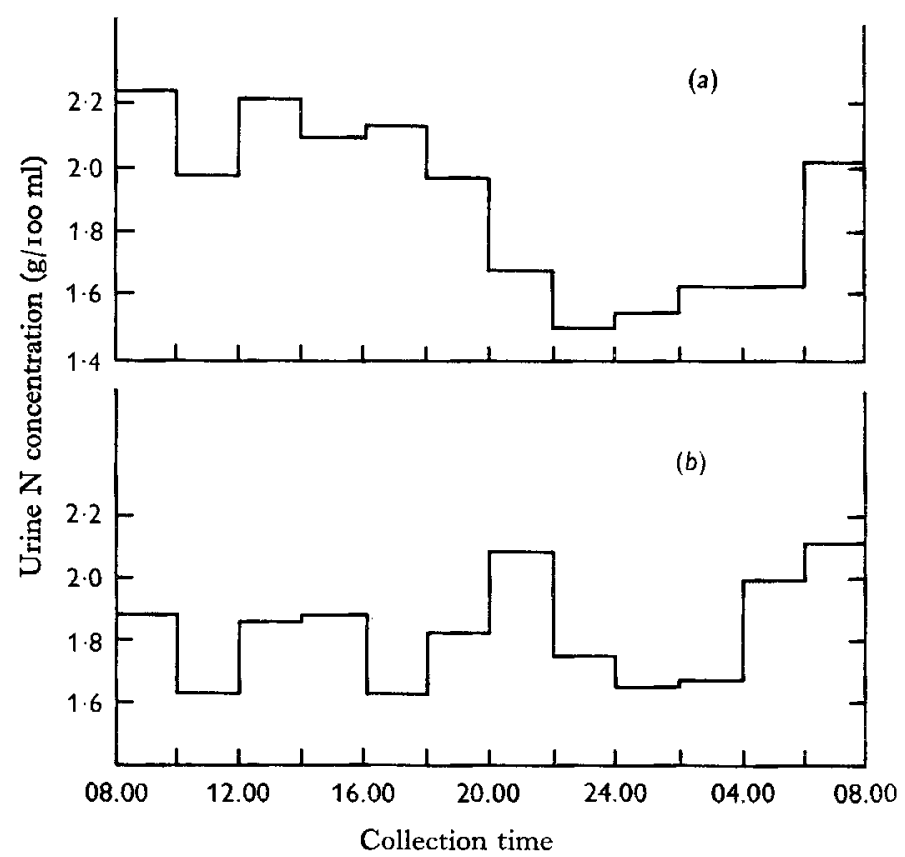

Fig. 5. Diurnal variation in urine total nitrogen concentration in sheep given feed (a) once, at $10.00 \mathrm{~h}$, or $(b)$ twenty-four times daily. (Mean values for six sheep for 2 days.) 


\section{Urinary $N$ excretion}

In Expt I the rate of excretion of urinary $\mathrm{N}$ was $0.6 \mathrm{~g} / \mathrm{h}$ in the $2 \mathrm{~h}$ after feeding. In the next $6 \mathrm{~h}$ it increased to a maximum of $\mathrm{I} \cdot 7 \mathrm{~g} / \mathrm{h}$ and then decreased to $0.37 \mathrm{~g} / \mathrm{h}$ at the $06.00 \mathrm{~h}$ collection (Fig. 6). The standard deviation with the 2-hourly collection was $\pm 0.48 \mathrm{~g} / \mathrm{h}$. Hourly feeding eliminated the diurnal variation, reduced the 2-hourly variance by $91 \%$ and the standard deviation to $\pm 0.12 \mathrm{~g} / \mathrm{h}$. The total quantity of $\mathrm{N}$ excreted in $48 \mathrm{~h}$ was the same with the two methods of feeding.

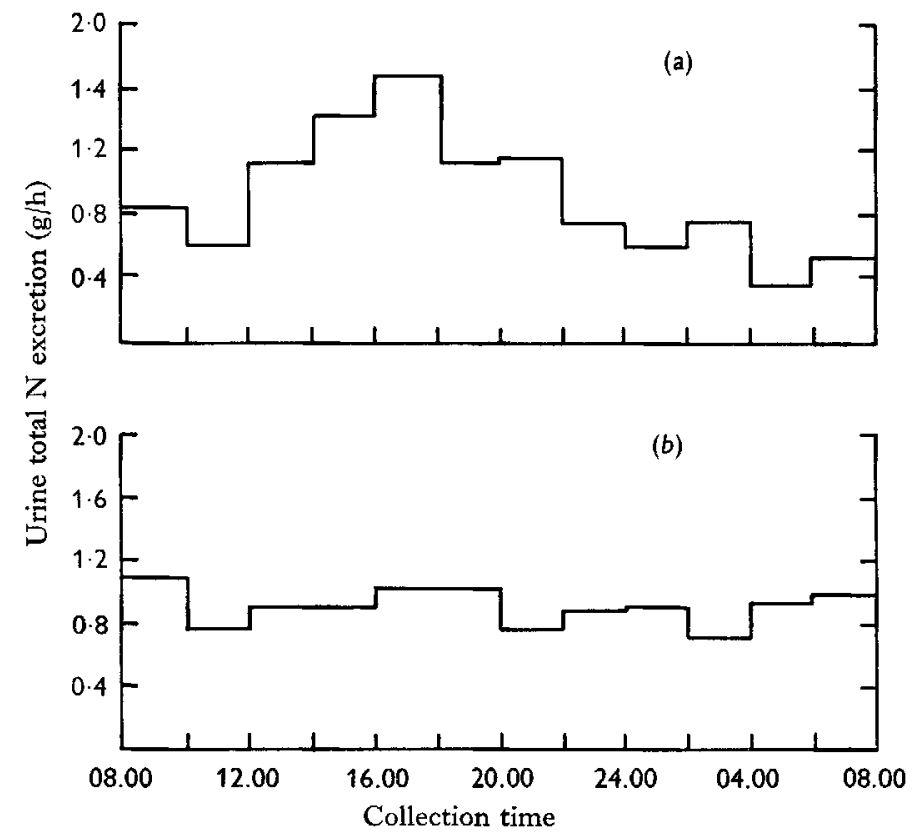

Fig. 6. Diurnal variation in urinary nitrogen excretion in sheep given feed $(a)$ once, at r $0.00 \mathrm{~h}$, or (b) twenty-four times daily. (Mean values for six sheep for 2 days.)

\section{ISCUSSION}

The machine described in this paper delivers weighed quantities of feed every hour for $24 \mathrm{~h}$. It has been used continuously for 18 months without missing a feed and has never delivered two feeds by overrunning. This machine has a number of advantages over a revolving automatic feeder described by Beeston (1964) which has only eight compartments compared with the twenty-four in our machine. The machine described by Beeston also requires space in front of the metabolism cages, and difficulty was reported in preventing sheep from gaining access to more than one feed container.

All the diurnal rhythms found with once daily feeding were eliminated by feeding every hour. In addition, the hourly feeding reduced the variation between $2 \mathrm{~h}$ collection periods by $47-9 \mathrm{I} \%$ according to the factor being measured. This result was achieved after only Io days of hourly feeding and is in agreement with those for 
rats (Brody, I945) when I week of continuous light and feeding at intervals of $3 \mathrm{~h}$ eliminated diurnal rhythms.

The automatic feeder requires refilling at the same time each day and this diurnal pattern of management could introduce diurnal variations in behaviour and metabolism. This influence could be eliminated by keeping the automatic feeder in a separate room directly above the sheep cages or by using more than twenty-four trays which could then be filled at any time of the day or night.

The findings reported in this paper for total output of faecal dry matter, faeces dry-matter concentration, total urine flow, urine specific gravity, urine N concentration and the total $\mathrm{N}$ content of the urine show that feeding at hourly intervals in a constant environment eliminates the diurnal pattern of many body functions. Thus the technique described should prove useful in many physiological and biochemical studies.

The helpful suggestions of Dr R. Milford, officer-in-charge of the Cooper Laboratory, and the technical assistance of Miss A. Hoxey and Messrs H. J. Kiers and G. A. Taylor are gratefully acknowledged.

\section{REFERENCES}

Beeston, J. W. U. ( ( 964). Proc. Aust. Soc. Anim. Prod. 5, 357.

Brody, S. (1945). Bioenergetics and Growth. Ch. 9. New York: Reinhold Publishing Corp.

Meyer, J. H., Gaskill, R. L., Stoewsand, G. S. \& Weir, W. C. (1959). F. Anim. Sci. 18, 336.

Morris, J. A. (1 96r). Poult. Sci. 40, 995.

Murray, M. G., Reid, R. S. \& Sutherland, T. M. (1962). F. Physiol., Lond. 164, 26 P.

Pritchard, G. I. \& Heaney, D. P. (1963). Can. F. Anim. Sci. 43, 226.

EXPLANATION OF PLATE

Automatic feeder for sheep. 
British Gournal of Nutrition, Vol. 20, No. 4

Plate I

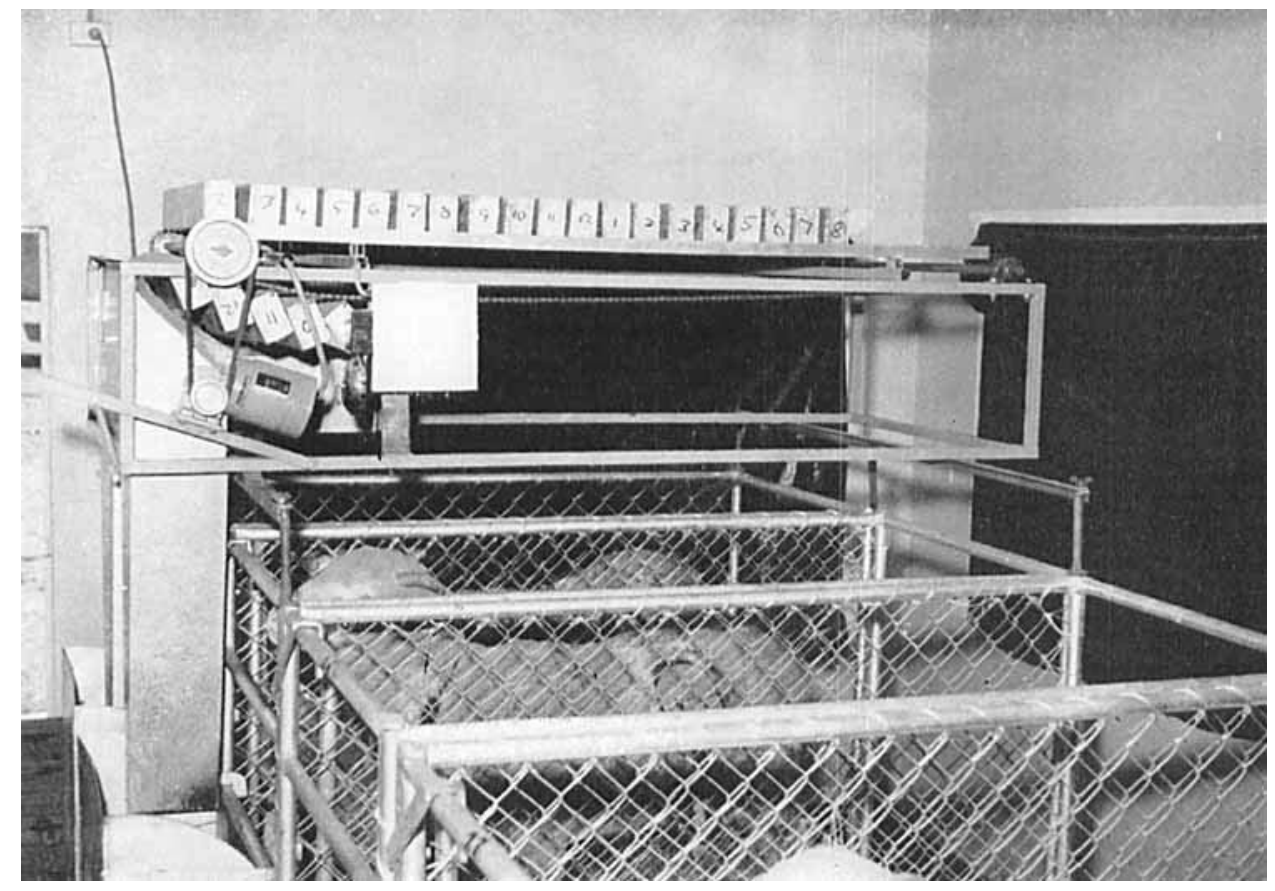

